\title{
Functional Impairment in Patients with Panic Disorder
}

\author{
Hyun-Ju Kim ${ }^{1 *}$, Ji Eun Kim ${ }^{2 *}$, and Sang-Hyuk Lee ${ }^{1,3 凶}$ \\ 1'Department of Psychiatry, CHA Bundang Medical Center, CHA University School of Medicine, Seongnam, Republic of Korea \\ ${ }^{2}$ Graduate School of Social Welfare, Yonsei University, Seoul, Republic of Korea \\ ${ }^{3}$ Department of Clinical Pharmacology and Therapeutics, CHA Bundang Medical Center, CHA University School of Medicine, Seongnam, \\ Republic of Korea
}

\begin{abstract}
Objective Anxiety and depression and sociodemographic factors such as age, gender, education level, income, and marital status among people with panic disorder (PD) are associated with functional impairment in the areas of work, social, and family. Although both PD-specific scales such as the Panic Disorder Severity Scale (PDSS) and Anxiety Sensitivity Inventory-Revised (ASI-R) and early trauma have been investigated, their relationship with functional impairment in PD patients has not been clarified.

Methods This study included 267 PD patients. The PDSS, Beck Depression Inventory (BDI), ASI-R, and Early Trauma Inventory were used. Pearson's correlation and multiple linear regression analyses were performed. The Sheehan Disability Scale (SDS) was administered to assess the functional impairment level in PD patients.

Results Our findings showed that high levels of PDSS, BDI, and ASI-R were significantly correlated with the functional impairment among PD patients. Multiple regression analyses showed that PDSS, BDI, and ASI-R can predict the functional impairment levels, and PDSS and ASI-R were significantly associated with lost and underproductive days in PD patients.

Conclusion Panic-specific symptoms, depression, and AS are associated with functional impairment level in PD patients. Elevated symptom severity can play a role by affecting productivity and daily responsibilities in PD patients.
\end{abstract}

Psychiatry Investig 2021;18(5):434-442

Key Words Panic disorder, Functional impairment, Predictors, Anxiety sensitivity, Early trauma.

\section{INTRODUCTION}

Panic disorder (PD) is associated with other psychiatric and medical comorbidity, use of health services, functional impairment, and impaired quality of life, which consequently leads to serious social burdens. ${ }^{1-3}$ Individuals with a panic-specific symptom such as panic attack have a higher degree of marked impairment in work, social, and family functions than individuals without this symptom. ${ }^{4-6}$ In addition, many $P D$ patients undergo a chronic and recurrent course and depression that may reflect either demoralization or an attenuated form of a major depressive disorder. ${ }^{7}$ Therefore, $\mathrm{PD}$ is a chronic and re-

Received: December 10, 2020 Revised: January 18, 2021

Accepted: February 20, 2021

$\triangle$ Correspondence: Sang-Hyuk Lee, MD, PhD

Department of Psychiatry, CHA Bundang Medical Center, CHA University School of Medicine, 59 Yatap-ro, Bundang-gu, Seongnam 13496, Republic of Korea

Tel: +82-31-780-5694, Fax: +82-31-780-5862, E-mail: drshlee@cha.ac.kr

*These authors contributed equally to this work.

(a) This is an Open Access article distributed under the terms of the Creative Commons Attribution Non-Commercial License (https://creativecommons.org/licenses/bync/4.0) which permits unrestricted non-commercial use, distribution, and reproduction in any medium, provided the original work is properly cited. current anxiety disorder causing impairment in occupational, social, or other important function areas and thereby decreasing quality of life. ${ }^{8,9}$

Functional impairment has been defined as limitations in an individual's ability to perform activities related to daily life, such as social, physical, and interpersonal activities. ${ }^{10}$ There are various measures such as the Medical Outcomes Study (MOS), 36-item Short-Form Health Survey (SF-36), ${ }^{11,12}$ and World Health Organization Quality Of Life-100 (WHOQOL-100) ${ }^{13,14}$ evaluate quality of life in PD patients. However, quality of life, which is defined from various subjective perspectives such as function in daily activities and work, physical health, perceptions of social relationships, economic status, and an subjective sense of well-being, is different from functional impairment. ${ }^{15}$

Several instruments are known to assess functional impairment such as the Diagnostic and Statistical Manual of Mental Disorders (DSM)'s Global Assessment of Functioning (GAF) ${ }^{16}$ scale and World Health Organization Disability Assessment Schedule (WHODAS). ${ }^{17}$ Moreover, the Sheehan Disability Scale $(\mathrm{SDS})^{18-20}$ is a well-known simple self-report instrument and has adequate levels of reliability and validity for patients with 
any of the following six psychiatric disorders: PD, general anxiety disorder (GAD), major depressive disorder (MDD), obsessive-compulsive disorder (OCD), drug dependence, and alcohol dependence. ${ }^{21}$ Moreover, SDS is unlikely to burden PD patients because it uses short, three-item questionnaires in a clinical setting.

For the above-mentioned reasons, many previous studies have shown that there were several risk factors of functional impairment in work and interpersonal relationships such as anxiety and depressive symptoms, older age, lower education level, and neuroticism in anxiety and depressive disorders. ${ }^{22-25}$ Both early trauma and PD-specific scales such as the Panic Disorder Severity Scale (PDSS) ${ }^{26,27}$ and Anxiety Sensitivity Inventory-Revised (ASI-R) ${ }^{28-31}$ assess anxiety sensitivity (AS), which is defined as a fundamental fear of anxiety-related sensations, distinct from derivative ones. In addition, AS is a concept distinguishable from trait anxiety. The former represents a particular tendency to respond fearfully to anxiety symptoms, whereas the latter to generally respond fearfully to stressors. ${ }^{30}$ Moreover, defined as fear of anxiety symptoms, AS differs from phobia or agoraphobia in that it is more motivational and logical because individuals with high AS usually explain the logical reasons for fear of anxiety symptoms. ${ }^{32}$ However, these instruments have not been studied in terms of their relationship with functional impairment in PD patients.

Additionally, with the recent trend of modern social changes that are becoming more prominent in outpatient clinical settings, it seems many physicians have not paid attention to functional impairment in initial assessments among people with PD. Panic-specific symptoms or symptoms of depression may indicate problems in the initial assessment, but we tend to incorrectly assess the functional status of PD patients. Therefore, even if some symptoms remain in PD patients, minimizing functional impairment through proper intervention can improve the quality of life and increase their satisfaction in life. ${ }^{33}$

Therefore, the purpose of this study was to examine whether the history of early trauma, symptom severity, and AS were predictors of functional impairment using SDS in PD patients. In addition, we conducted analyses to identify other predictors of functional impairment in PD patients, including sociodemographic and other clinical factors. We hypothesized that PD patients with a history of early trauma and with a higher level of BDI, PDSS, and ASI-R at the initial assessment might have a severe functional impairment.

\section{METHODS}

\section{Participants}

Two hundred sixty-seven individuals among 327 PD patients were enrolled in the study, which was conducted from
2011 to 2020. Sixty participants were excluded due to missing values in assessment measures. Participants were recruited from among PD patients who were treated in the Department of Psychiatry at CHA Bundang Medical Center.

Participants with PD were recruited if they were between 18 and 70 years of age and met the Diagnostic and Statistical Manual of Mental Disorders, Fourth Edition, Text Revision (DSM-IV-TR) criteria for PD with or without agoraphobia, as determined with the Structured Clinical Interview for DSMIV. Individuals with a primary diagnosis of any schizophrenia, $\mathrm{MDD}$, anxiety disorders other than PD, other substance use disorders including alcohol use disorder, intellectual disability, major medical disorders including neurological disorders, and pregnancy were excluded.

The personal and family histories of PD patients were collected through interviews and self-report data. Interview and clinical assessments were performed during their first visit to the hospital. Participants were administered self-report scales on the same day to rule out memory recall bias after medication commencement. All study procedures adhered to the Institutional Review Board regulations and principles of Good Clinical Practice at the CHA Bundang Medical Center. Written informed consent was obtained after the methods and purpose of the study were explained to participants (2019-05-030, 2018-06-029, 2011-11-164).

\section{Clinical assessments}

The Early Trauma Inventory Self Report-Short Form (ETISRSF), BDI, PDSS, ASI-R, and SDS were administered.

Early trauma was assessed with the Korean version of the ETISR-SF, which was administered at baseline. The Korean version of the ETISR-SF is a highly reliable (Cronbach's alpha= 0.869 ) and valid instrument; its scores significantly correlate with those of the Childhood Trauma Questionnaire-Short Form $(\mathrm{r}=0.691){ }^{34}$ The scale consists of 27 "yes" or "no" questions and consists of four domains-general, physical, emotional, and sexual trauma experienced before 18 years of age. Each domain consists of $11,5,5$, and 6 questions, respectively.

The BDI is a 21 -item instrument that measures depressive symptoms. Internal consistency at pretreatment was high in the previous study (Cronbach's alpha: 0.87). ${ }^{35}$ In this study, we administrated the Korean BDI (K-BDI), ${ }^{36}$ which has adequate internal consistency (Cronbach's alpha: 0.85) and discriminant validity.

The PDSS measures all PD dimensions, including panic attack, anticipatory anxiety, panic-related phobias, wellness, severity of all symptoms, and impairment. The PDSS is a 7-item self-rated measure of PD-specific symptoms (e.g., "During the past week, how much have you worried or felt anxious about when your next panic attack would occur or about fears re- 
lated to the attacks?"). Responses are based on a 5-point Likert scale, ranging from 0 to 4 . The Korean PDSS was found to have strong reliability and validity, and internal consistency was high in the previous study (Cronbach's alpha: 0.88). ${ }^{37}$

All subjects' AS levels were assessed using the Korean version of the ASI, ${ }^{38,39}$ which is the most commonly used to measure AS. The scale consists of four domains: 1) fear of a respiratory symptom; 2) fear of a cardiovascular symptom; 3) fear of a publicly observable anxious reaction; 4), and fear of cognitive dyscontrol. The ASI-R is an expanded version ${ }^{40}$ of the ASI scale and includes 36 items. Total scores range from 0 to 144. The internal consistency coefficient of the Korean version was 0.92 , and its test-retest reliability was 0.82 .

Developed by David Sheehan, SDS is a brief, self-rated, costeffective instrument to measure functional impairment levels by psychiatric or medical symptoms in three major domains showing adequate levels of reliability (Cronbach's alpha: 0.89) and validity in the study of PD patients: ${ }^{19,20} 1$ ) work/school, 2) social life/leisure, and 3) family life/home responsibilities. These three domains are measured via a visual analog scale ranging from 0 (not at all), 1-3 (mildly), 4-6 (moderately), 7-9 (markedly), to 10 (extremely). Additionally, the question, "days lost during a week," is used to measure how many days in the last week normal daily routine responsibilities, such as school or work, could not be carried out due to symptoms. ${ }^{41}$ Moreover, the last question, "days unproductive during a week," is a measure of how many days in the last week individuals felt so impaired by their symptoms due to reduced their productivity in school or work, even though they have performed routine tasks over the past week. ${ }^{41}$

\section{Statistical analyses}

To analyze the sociodemographic characteristics and clinical symptom severity of PD patients, we use the chi-square test and Student's t-tests. In addition, a Student's t-test was applied to determine the association between categorical variables and several factors of SDS. Pearson's correlation analysis was used to assess the relationships among continuous variables such as functional impairment, history of early trauma, depression, severity of panic symptoms, and AS.

Furthermore, after controlling for sociodemographic characteristics and clinical symptom severity, multiple linear regression analyses were used to assess several factors affecting the levels of functional impairment in PD patients. All statistical analyses were performed using SPSS software version 24.0 (IBM Corp., Armonk, NY, USA). All reported probability values were two-sided with a p-value less than 0.05 considered statistically significant.

\section{RESULTS}

\section{General characteristics of participants}

The sociodemographic and clinical characteristics, and functional impairment levels of participants with PD are presented in Table 1.

\section{Characteristics of clinical symptoms and functional impairment}

The severity of clinical symptoms according to sociodemographic findings were shown in Table 2.

The functional impairment levels were also presented in Table 3. Significant differences in functional impairment levels

Table 1. General characteristics and the functional impairment levels in patients with panic disorder

\begin{tabular}{|c|c|c|}
\hline \multirow{2}{*}{ Sociodemographics } & \multicolumn{2}{|c|}{ Patients with PD $(\mathrm{N}=267)$} \\
\hline & \multicolumn{2}{|c|}{ Values or mean $\pm S D$} \\
\hline Age (years) & \multicolumn{2}{|c|}{$38.84 \pm 11.24$} \\
\hline \multicolumn{3}{|l|}{ Gender } \\
\hline Male & \multicolumn{2}{|c|}{$158(48.00)$} \\
\hline Female & \multicolumn{2}{|c|}{$171(52.00)$} \\
\hline \multicolumn{3}{|l|}{ Education } \\
\hline High school or less & \multicolumn{2}{|c|}{$105(32.30)$} \\
\hline College or more & \multicolumn{2}{|c|}{$220(67.70)$} \\
\hline \multicolumn{3}{|l|}{ Monthly income } \\
\hline Below $1,800 \$$ USD & \multicolumn{2}{|c|}{$19(5.90)$} \\
\hline Above $1,800 \$$ USD & \multicolumn{2}{|c|}{$304(94.10)$} \\
\hline \multicolumn{3}{|l|}{ Marital status } \\
\hline Living with partner & \multicolumn{2}{|c|}{$193(59.20)$} \\
\hline Living without partner & \multicolumn{2}{|c|}{$133(40.80)$} \\
\hline Clinical characteristics & $\begin{array}{l}\text { Values or } \\
\text { mean } \pm \text { SD }\end{array}$ & (Min-max) \\
\hline Agoraphobia, yes & $84(26.10)$ & \\
\hline $\begin{array}{l}\text { Early trauma (ETISR-SF) } \\
\text { (total sum of four subtypes) }\end{array}$ & $4.83 \pm 3.98$ & $(0-19)$ \\
\hline Depression (BDI) & $15.08 \pm 9.31$ & $(0-50)$ \\
\hline Panic-specific symptoms (PDSS) & $11.15 \pm 5.99$ & $(0-27)$ \\
\hline Anxiety sensitivity (ASI-R) & $47.41 \pm 26.64$ & $(0-136)$ \\
\hline \multicolumn{3}{|l|}{ Functional impairment (SDS) } \\
\hline Work/school & $4.54 \pm 3.15$ & $(0-10)$ \\
\hline Social life & $4.12 \pm 3.19$ & $(0-10)$ \\
\hline Family life/home responsibilities & $3.95 \pm 3.11$ & $(0-10)$ \\
\hline Days lost during a week & $1.69 \pm 2.18$ & $(0-7)$ \\
\hline $\begin{array}{l}\text { Days underproductive during a } \\
\text { week }\end{array}$ & $2.59 \pm 2.43$ & $(0-7)$ \\
\hline
\end{tabular}

Values represent count (percent) or mean \pm SD. SD: standard deviation, Min: minimum, Max: maximum, PD: panic disorder, ETISRSF: Early Trauma Inventory Self Report-Short Form, BDI: Beck Depression Inventory, PDSS: Panic Disorder Severity Scale, ASI-R: Anxiety Sensitivity Index-Revised, SDS: Sheehan Disability Scale 
HJ Kim et al.

Table 2. Clinical characteristics by sociodemographic category in patients with panic disorder

\begin{tabular}{|c|c|c|c|c|c|c|c|c|}
\hline \multirow{3}{*}{ Sociodemographics } & \multicolumn{8}{|c|}{ Clinical characteristics } \\
\hline & \multicolumn{2}{|c|}{$\begin{array}{l}\text { Early trauma } \\
\text { (ETISR-SF) }\end{array}$} & \multicolumn{2}{|c|}{$\begin{array}{l}\text { Depression } \\
\text { (BDI) }\end{array}$} & \multicolumn{2}{|c|}{$\begin{array}{c}\text { Panic-specific symptoms } \\
\text { (PDSS) }\end{array}$} & \multicolumn{2}{|c|}{$\begin{array}{c}\text { Anxiety sensitivity } \\
\text { (ASI-R) }\end{array}$} \\
\hline & Mean (SD) & $\mathrm{t}(\mathrm{p})$ & Mean (SD) & $\mathrm{t}(\mathrm{p})$ & Mean (SD) & $\mathrm{t}(\mathrm{p})$ & Mean (SD) & $\mathrm{t}(\mathrm{p})$ \\
\hline \multicolumn{9}{|l|}{ Gender } \\
\hline Male & $5.12(3.82)$ & -1.268 & $14.17(8.81)$ & 1.698 & $11.40(6.37)$ & -0.719 & 43.76 & $2.359^{*}$ \\
\hline Female & $4.55(4.12)$ & $(0.206)$ & $15.94(9.72)$ & $(0.091)$ & $10.92(5.62)$ & $(0.473)$ & 50.87 & $(0.019 *)$ \\
\hline \multicolumn{9}{|l|}{ Education } \\
\hline High school or less & $5.02(4.22)$ & -0.648 & $16.59(10.54)$ & -1.812 & $11.56(6.27)$ & -0.008 & $44.67(26.48)$ & 1.255 \\
\hline College or more & $4.70(3.90)$ & $(0.517)$ & $14.42(8.59)$ & $(0.072)$ & $11.15(5.91)$ & $(0.994)$ & $48.79(26.81)$ & $(0.210)$ \\
\hline \multicolumn{9}{|l|}{ Monthly income } \\
\hline Below $1,800 \$$ USD & $6.69(4.88)$ & -1.894 & $20.05(10.79)$ & $-2.415^{*}$ & $10.94(6.81)$ & 0.154 & $45.00(27.96)$ & 0.372 \\
\hline Above $1,800 \$$ USD & $4.76(3.92)$ & $(0.059)$ & $14.78(9.13)$ & $\left(0.016^{*}\right)$ & $11.17(5.99)$ & $(0.878)$ & $47.56(26.73)$ & $(0.710)$ \\
\hline \multicolumn{9}{|l|}{ Marital status } \\
\hline Living with partner & $4.08(3.50)$ & $-3.704^{\dagger}$ & $13.32(8.33)$ & $-4.089^{\dagger}$ & $10.10(5.75)$ & $-3.680^{\dagger}$ & $46.39(25.90)$ & -0.685 \\
\hline Living without partner & $5.80(4.37)$ & $\left(0.000^{\dagger}\right)$ & $17.45(9.58)$ & $\left(0.000^{\dagger}\right)$ & $12.55(6.02)$ & $\left(0.000^{\dagger}\right)$ & $48.49(27.27)$ & $(0.494)$ \\
\hline
\end{tabular}

${ }^{*} \mathrm{p}<0.05,{ }^{\dagger} \mathrm{p}<0.001$. ETISR-SF: Early Trauma Inventory Self Report-Short Form, BDI: Beck Depression Inventory, PDSS: Panic Disorder Severity Scale, ASI-R: Anxiety Sensitivity Index-Revised, SD: standard deviation

Table 3. Levels of functional impairment by sociodemographic characteristics in patients with panic disorder

\begin{tabular}{|c|c|c|c|c|c|c|c|c|c|c|}
\hline \multirow{3}{*}{ Sociodemographics } & \multicolumn{10}{|c|}{ Functional impairment (SDS) } \\
\hline & \multicolumn{2}{|c|}{ Work/school } & \multicolumn{2}{|c|}{ Social life } & \multicolumn{2}{|c|}{$\begin{array}{c}\text { Family life/home } \\
\text { responsibilities }\end{array}$} & \multicolumn{2}{|c|}{$\begin{array}{c}\text { Days lost } \\
\text { during a week }\end{array}$} & \multicolumn{2}{|c|}{$\begin{array}{c}\text { Days underproductive } \\
\text { during a week }\end{array}$} \\
\hline & Mean (SD) & $\mathrm{t}(\mathrm{p})$ & Mean (SD) & $\mathrm{t}(\mathrm{p})$ & Mean (SD) & $\mathrm{t}(\mathrm{p})$ & Mean (SD) & $\mathrm{t}(\mathrm{p})$ & Mean $(\mathrm{SD})$ & $\mathrm{t}(\mathrm{p})$ \\
\hline \multicolumn{11}{|l|}{ Gender } \\
\hline Male & $4.50(3.11)$ & 0.190 & $4.05(3.18)$ & 0.323 & $3.87(3.16)$ & 0.447 & $1.65(2.26)$ & 0.304 & $2.38(2.41)$ & 1.469 \\
\hline Female & $4.57(3.20)$ & $(0.849)$ & $4.17(3.22)$ & $(0.747)$ & $4.02(3.07)$ & $(0.655)$ & $1.73(2.11)$ & $(0.761)$ & $2.80(2.45)$ & $(0.143)$ \\
\hline \multicolumn{11}{|l|}{ Education } \\
\hline High school or less & $4.73(3.20)$ & -0.699 & $4.13(3.30)$ & -0.014 & $4.12(3.30)$ & -0.656 & $1.84(2.38)$ & -0.777 & $2.81(2.61)$ & -1.085 \\
\hline College or more & $4.46(3.14)$ & $(0.485)$ & $4.12(3.14)$ & $(0.989)$ & $3.87(3.02)$ & $(0.512)$ & $1.63(2.08)$ & $(0.456)$ & $2.47(2.33)$ & $(0.279)$ \\
\hline \multicolumn{11}{|l|}{ Monthly income } \\
\hline Below $1,800 \$$ USD & $4.83(3.76)$ & -0.375 & $4.05(3.27)$ & 0.095 & $3.95(3.24)$ & 0.029 & $1.28(1.41)$ & 0.825 & $3.22(2.53)$ & -1.151 \\
\hline Above $1,800 \$$ USD & $4.55(3.12)$ & $(0.708)$ & $4.13(3.20)$ & $(0.924)$ & $3.97(3.11)$ & $(0.977)$ & $1.71(2.21)$ & $(0.410)$ & $2.54(2.42)$ & $(0.251)$ \\
\hline \multicolumn{11}{|l|}{ Marital status } \\
\hline Living with partner & $4.18(3.07)$ & -2.371 & $3.74(3.17)$ & -2.402 & $4.03(3.06)$ & 0.667 & $1.53(2.17)$ & -1.390 & $2.27(2.40)$ & -2.687 \\
\hline $\begin{array}{l}\text { Living without } \\
\text { partner }\end{array}$ & $5.03(3.19)$ & $\left(0.018^{*}\right)$ & $4.61(3.13)$ & $\left(0.017^{*}\right)$ & $3.79(3.13)$ & $(0.505)$ & $1.89(2.15)$ & $(0.166)$ & $3.04(2.41)$ & $\left(0.008^{*}\right)$ \\
\hline
\end{tabular}

*p<0.05. SDS: Sheehan Disability Scale, SD: standard deviation

are observed in marital status. Regarding marital status, patients living without a partner showed significant functional impairment in work $(\mathrm{t}=-2.371, \mathrm{p}=0.018)$, social life $(\mathrm{t}=-2.402, \mathrm{p}=0.017)$ compared with those living with a partner. Also, underproductive days during the week were significant longer $(t=-2.687, p=$ 0.008 ) in single PD patients. There was no statistical difference in functional impairment by gender, education level, and household monthly income.

\section{Pearson's correlation with the levels of functional impairment}

The functional impairment levels in work, social, and family life showed significantly positive correlations with clinical symptoms such as history of early trauma, depression, severity of panic-specific symptoms and ASI-R ( $\mathrm{p}<0.01)$. Regarding age, younger patients experienced greater function impairment levels in work and social life than older patients with PD ( $\mathrm{p}<$ 0.01). Moreover, the correlations between the lost or underproductive days and clinical symptoms were positively signifi- 
cant $(\mathrm{p}<0.05)($ Table 4$)$.

\section{Predictors of functional impairment in patients with PD}

The results of multiple linear regression analyses used to determine the predictors of functional impairment in patients with PD are reported in Table 5. A total of 273 cases were used for analysis, with missing values excluded. These research models proved to be significant at the 0.001 level with no multicollinearity issue. The explanatory powers of these models were $37.5 \%$ in work $\left(\mathrm{R}^{2}=0.375\right), 37 \%$ in social $\left(\mathrm{R}^{2}=0.370\right)$, and $34.5 \%$ in family life $\left(\mathrm{R}^{2}=0.345\right)$. The additional linear regression anal-

Table 4. Pearson's correlation among variables in patients with panic disorder

\begin{tabular}{|c|c|c|c|c|c|c|c|c|c|}
\hline Variables & 1 & 2 & 3 & 4 & 5 & 6 & 7 & 8 & 9 \\
\hline${ }^{1}$ Age (years) & - & & & & & & & & \\
\hline${ }^{2}$ Early trauma (ETISR-SF) & $-0.248^{\ddagger}$ & - & & & & & & & \\
\hline${ }^{3}$ Depression (BDI) & $-0.241^{\ddagger}$ & $0.297^{\ddagger}$ & - & & & & & & \\
\hline${ }^{4}$ Panic-specific symptoms (PDSS) & $-0.203^{\ddagger}$ & $0.137^{*}$ & $0.403^{\ddagger}$ & - & & & & & \\
\hline${ }^{5}$ Anxiety sensitivity(ASI-R) & $-0.164^{\dagger}$ & $0.291^{\ddagger}$ & $0.580^{\ddagger}$ & $0.444^{\ddagger}$ & - & & & & \\
\hline \multicolumn{10}{|l|}{ Functional impairment (SDS) } \\
\hline${ }^{6}$ Work/school & $-0.167^{\dagger}$ & $0.242^{\ddagger}$ & $0.475^{\ddagger}$ & $0.501^{\ddagger}$ & $0.498^{\ddagger}$ & - & & & \\
\hline${ }^{7}$ Social life & $-0.146^{\dagger}$ & $0.160^{\dagger}$ & $0.468^{\ddagger}$ & $0.481^{\ddagger}$ & $0.511^{\ddagger}$ & $0.753^{\ddagger}$ & - & & \\
\hline${ }^{8}$ Family life/home responsibilities & 0.001 & $0.165^{\dagger}$ & $0.466^{\ddagger}$ & $0.414^{\ddagger}$ & $0.516^{\ddagger}$ & $0.692^{\ddagger}$ & $0.777^{\ddagger}$ & - & \\
\hline${ }^{9}$ Days lost during a week & -0.041 & $0.150^{*}$ & $0.369 \ddagger$ & $0.451^{\ddagger}$ & $0.381^{\ddagger}$ & $0.594^{\ddagger}$ & $0.521^{\ddagger}$ & $0.541^{\ddagger}$ & - \\
\hline${ }^{10}$ Days underproductive during a week & $-0.127^{*}$ & $0.193^{\dagger}$ & $0.459^{\ddagger}$ & $0.442^{\ddagger}$ & $0.428^{\ddagger}$ & $0.634^{\ddagger}$ & $0.597^{\ddagger}$ & $0.560^{\ddagger}$ & $0.695^{\ddagger}$ \\
\hline
\end{tabular}

${ }^{*} \mathrm{p}<0.05,{ }^{\dagger} \mathrm{p}<0.01,{ }^{\ddagger} \mathrm{p}<0.001$. ETISR-SF: Early Trauma Inventory Self Report-Short Form, BDI: Beck Depression Inventory, PDSS: Panic Disorder Severity Scale, ASI-R: Anxiety Sensitivity Index-Revised, SDS: Sheehan Disability Scale

Table 5. Multiple linear regression analyses predicting the levels of functional impairment in patients with panic disorder

\begin{tabular}{|c|c|c|c|c|c|c|c|c|c|c|}
\hline & \multicolumn{10}{|c|}{ Functional impairment (SDS) } \\
\hline & \multicolumn{2}{|c|}{ Work/school } & \multicolumn{2}{|c|}{ Social life } & \multicolumn{2}{|c|}{$\begin{array}{l}\text { Family life/home } \\
\text { responsibilities }\end{array}$} & \multicolumn{2}{|c|}{$\begin{array}{c}\text { Days lost } \\
\text { during a week }\end{array}$} & \multicolumn{2}{|c|}{$\begin{array}{c}\text { Days } \\
\text { underproductive } \\
\text { during a week }\end{array}$} \\
\hline & B & $\mathrm{t}$ & B & $\mathrm{t}$ & $\mathrm{B}$ & $\mathrm{t}$ & B & $\mathrm{t}$ & B & $\mathrm{t}$ \\
\hline \multicolumn{11}{|l|}{ Sociodemographics } \\
\hline Age & -0.052 & -0.869 & -0.014 & -0.228 & 0.105 & 1.733 & 0.054 & 0.822 & -0.062 & -0.979 \\
\hline Gender (male) & 0.009 & 0.173 & 0.036 & 0.707 & 0.028 & 0.546 & -0.014 & -0.248 & -0.056 & -1.027 \\
\hline Education (high school or less) & 0.067 & 1.302 & -0.025 & -0.478 & -0.009 & -0.175 & 0.025 & 0.437 & 0.058 & 1.036 \\
\hline $\begin{array}{l}\text { Monthly income (below } 1,800 \$ \\
\text { USD) }\end{array}$ & 0.022 & 0.447 & 0.009 & 0.175 & -0.014 & -0.273 & -0.069 & -1.216 & 0.063 & 1.163 \\
\hline $\begin{array}{l}\text { Marital status (living without } \\
\text { partner) }\end{array}$ & -0.001 & -0.010 & 0.033 & 0.560 & -0.098 & -1.664 & 0.013 & 0.196 & 0.003 & 0.042 \\
\hline \multicolumn{11}{|l|}{ Clinical characteristics } \\
\hline Early trauma (ETISR-SF) & 0.099 & 1.851 & 0.001 & 0.023 & 0.043 & 0.790 & 0.007 & 0.117 & 0.019 & 0.324 \\
\hline Depression (BDI) & 0.183 & $2.835^{\dagger}$ & 0.244 & $3.769^{\ddagger}$ & 0.284 & $4.311^{\ddagger}$ & 0.157 & $2.127^{*}$ & 0.212 & $2.983^{\dagger}$ \\
\hline Panic-specific symptoms (PDSS) & 0.298 & $5.185^{\ddagger}$ & 0.270 & $4.667^{\ddagger}$ & 0.198 & $3.384^{\dagger}$ & 0.317 & $4.835^{\ddagger}$ & 0.295 & $4.715^{\ddagger}$ \\
\hline Anxiety sensitivity (ASI-R) & 0.210 & $3.166^{\dagger}$ & 0.230 & $3.458^{\dagger}$ & 0.255 & $3.770^{\ddagger}$ & 0.137 & 1.787 & 0.115 & 1.577 \\
\hline Constant & \multicolumn{2}{|c|}{0.690} & \multicolumn{2}{|c|}{-0.133} & \multicolumn{2}{|c|}{-1.236} & \multicolumn{2}{|c|}{-1.077} & \multicolumn{2}{|c|}{0.381} \\
\hline $\mathrm{F}$ & \multicolumn{2}{|c|}{$17.372^{\ddagger}$} & \multicolumn{2}{|c|}{$16.951^{\ddagger}$} & \multicolumn{2}{|c|}{$15.389^{\ddagger}$} & \multicolumn{2}{|c|}{$9.019^{\ddagger}$} & \multicolumn{2}{|c|}{$11.636^{\ddagger}$} \\
\hline $\mathrm{R}^{2}$ & \multicolumn{2}{|c|}{0.375} & \multicolumn{2}{|c|}{0.370} & \multicolumn{2}{|c|}{0.345} & \multicolumn{2}{|c|}{0.250} & \multicolumn{2}{|c|}{0.298} \\
\hline Adj $R^{2}$ & \multicolumn{2}{|c|}{0.353} & \multicolumn{2}{|c|}{0.348} & \multicolumn{2}{|c|}{0.323} & \multicolumn{2}{|c|}{0.222} & \multicolumn{2}{|c|}{0.272} \\
\hline
\end{tabular}

Reference group: gender (female), education (college or more), monthly income (above 1,800\$ USD), marital status (living with partner). ${ }^{*} \mathrm{p}<0.05,{ }^{\dagger} \mathrm{p}<0.01,{ }^{\ddagger} \mathrm{p}<0.001$. SDS: Sheehan Disability Scale, ETISR-SF: Early Trauma Inventory Self Report-Short Form, BDI: Beck Depression Inventory, PDSS: Panic Disorder Severity Scale, ASI-R: Anxiety Sensitivity Index-Revised 
ysis models of the absence and inefficacy days were significant $(\mathrm{p}<0.001)$. Their explanatory powers were $25 \%$ in absence days $\left(\mathrm{R}^{2}=0.250\right)$ and $29.8 \%$ in the model of inefficacy days $\left(\mathrm{R}^{2}=0.298\right)$.

The levels of functional impairment were significantly associated with the scores of BDI, PDSS, and ASI-R after controlling sociodemographic variables. In detail, the more symptoms of depressive mood was significantly associated with greater functional impairment in the area of work $(B=0.183, p=0.005)$, social $(\mathrm{B}=0.244, \mathrm{p}<0.001)$, and family life $(\mathrm{B}=0.284, \mathrm{p}<0.001)$. The high PDSS scores showed significant associations with impaired functions in work $(B=0.298, p<0.001)$, social $(B=0.270$, $\mathrm{p}<0.001)$, and family life $(\mathrm{B}=0.198, \mathrm{p}=0.001)$. Also, ASI-R scores were associated with the levels of functional disabilities significantly in work $(B=0.210, p=0.002)$, social $(B=0.230, p=0.001)$, and family life $(B=0.255, \mathrm{p}<0.001)$.

However, the presence of agoraphobia or severity of symptoms in patients with PD has shown results that do not significantly predict both the three major domains of evaluating levels of functional impairment and the remaining two categories in SDS. In addition, no association with early trauma and sociodemographic characteristics such as age, gender, education level, income and marital status was found with the functional impairment in PD patients regarding work, social, and family life.

In addition, the lost and underproductive days during a week were predicted with the higher BDI scores $(p<0.05)$, and PDSS scores $(p<0.001)$. However, the scores of ETISR-SF and sociodemographic characteristics were not significant in these two categories.

\section{DISCUSSION}

Using multiple linear regression analyses with SDS domains as dependent variables, this is the study to demonstrate that panic-specific symptoms, depression, and AS may be significantly associated with the functional impairment level in PD patients. The principal findings of this study suggested that PD patients who have a higher level of panic-specific symptoms, depression, and AS may have the lower functional impairment levels in three areas of functioning: work, social, and family life. However, this was not unexpected, early trauma cannot significantly be related to functional impairment among PD patients. In addition, the sociodemographic factors such as age, education level, household income, and marital status might not significantly affect functional impairment in PD patients.

The study results demonstrated that the functional impairment of three areas is positively associated with panic-specific symptom and depression in PD patients. Our finding was consistent with the previous finding that more severe symptomatology such as the anticipatory anxiety, fear intensity, and frequency of panic attacks was related to greater functional im- pairment in work, social, and family life among PD patients. ${ }^{42}$ Especially, our finding that anxiety and phobic avoidance were significantly associated with functional impairment in social and work areas among PD patients is explainable, given that home is considered the safest place by PD patients and they usually seem afraid to leave. ${ }^{43}$ In social situations, individuals with PD might fear and or be embarrassed by having a panic attack in front of others, and the results were correlated with impairments in social and marital functioning. ${ }^{44}$

Furthermore, a bi-directional relationship between depressive symptoms and functional impairment in anxiety and mood disorders could be suggested in people with PD. ${ }^{45,46}$ One possible explanation is that the cognitive and behavior manifestations of depression might give rise to social functional impairment on the one hand, which might lead to lasting depression due to rejection. ${ }^{47}$ However, more research is needed to examine the relationship between symptom severity of depression and functional impairment in PD patients.

In addition, our study shows that AS at initial assessment predicted the increased the risk of functional impairment in three areas among PD patients, which was consistent with a previous study. ${ }^{48}$ However, it was unclear by which mechanism the high AS was correlated with impairment of social and work functioning. It is assumed that individuals with higher AS may perceive their functional status more negatively than individuals with lower AS in various social situations among PD patients. However, additional studies are needed to examine the relationship between AS and functional impairment among PD patients.

However, our findings indicated that the presence of agoraphobia does not have a significant effect on three major categories of evaluating functional impairment in patients with PD. Previous studies have suggested that the presence of agoraphobia can affect the severity of PD symptoms and treatment outcomes, ${ }^{49,50}$ but it is not yet clear whether this directly affects the levels of functional impairment in patients with PD.

This study demonstrated that early trauma cannot significantly increase the risk of functional impairment in PD patients. Some studies have examined the relationship between early trauma and functional impairment in bipolar disorder. ${ }^{51,52}$ One possible explanation of this finding is that individuals with exposure to early trauma with post-traumatic stress symptoms were associated with the high levels of cortisol compared to individuals without exposure to early trauma, which might be driving functional impairment. ${ }^{53}$ Cortisol levels predict a decrease in the volume of the hippocampus and the prefrontal cortex volume, which are involved in memory processing and executive function, both of which are critical functions of learning. For another reason, early emotional trauma was related to functional impairment in SAD patients, especially because of 
the association between greater depression and lower self-esteem. ${ }^{54}$ Additionally, we studied PD patients of acute-care at a hospital in an early phase, and there is a possibility that the effect size of ETISR-SF was not as large as other measurements, so it was not reflected in our results. Also, it is possible that most PD patients maintain minimal functions levels in their daily lives, even if they suffer from symptoms.

Our findings indicated that sociodemographic factors such as age, education level, household income, and marital status were not strong predictors of functional impairment in $\mathrm{PD}$ patients. A previous finding reported that older age and low education levels significantly contributed to functional impairment in general health and physical functioning among PD patients. ${ }^{24}$ By contrast, our study included relatively younger PD patients than this previous study, and showed that younger people were more likely to have functional impairment in their social and occupational lives.

The relationship between education level and functional impairment in PD patients is not clear. A previous study showed that lower household income predicted a more rapid decrease in functional impairment among individuals with depression or anxiety symptoms. ${ }^{23}$ However, another study found that household income was not significantly correlated with social functioning impairments in other anxiety disorders such as posttraumatic stress disorder. ${ }^{55}$ It seems that educational level, household income, and marital status did not affect the functional impairment level in our findings.

Also, marital status did not significantly predict three areas of functional impairment, even though the significance was trend level, especially in the family area. Previous research showed single marital status was negatively associated with quality of life which measures a dimension similar to the functional impairment in PD patients. ${ }^{5}$ It has been reported that the association between marital difficulties and PD symptom severities was well known. ${ }^{56}$ However, our findings using SDS, which focused on functional impairment in various areas including work, social, and family life, suggested it was negative.

In addition, our findings showed that panic-specific symptoms and depression at the acute phase significantly reduced the daily responsibilities and productivity in PD patients. Panic-specific symptoms might cause individuals with $\mathrm{PD}$ to miss work or impair their occupational performance. Another study suggested that depression in subthreshold-depressive adolescent were associated with the increased risk of daily responsibility. ${ }^{57}$ Consequently, individuals with PD tend to experience higher unemployment rates and are less productive at work than their asymptomatic coworkers. ${ }^{58,59}$

Therefore, our study findings highlighted the importance of assessing the symptom severity and AS at the initial assessment and suggested that early interventions to reduce the panic-spe- cific symptoms, depression, and AS through pharmacotherapy and cognitive-behavioral therapy (CBT) for minimizing functional impairment in PD patients were needed.

Our study had several limitations. First, this study relied on retrospective self-reports or memory in evaluating early trauma in PD patients. Therefore, we could not completely rule out the possibility of recall bias in evaluating the history of early trauma. Second, we recruited PD patients whose symptoms developed in the early phase, from an acute-care hospital. Low proportions of $\mathrm{PD}$ patients with depressed episodes at the longterm follow-up, as usually shown in the natural course of PD, were included. Consequently, selection bias might have affected the prediction of functional impairment in PD patients.

In conclusion, the current study suggested that panic-specific symptoms, depression, and AS can be associated with the levels of functional impairment on work, social, and family areas in PD patients. However, the history of early trauma and several sociodemographic factors such as age, education level, household income, and marital status did not significantly predict functional impairment in PD patients. Especially, panicspecific symptoms and depression can play a role by affecting daily responsibilities and productivity in PD patients. Therefore, we should apply proper interventions such as pharmacological treatment and CBT in PD patients to minimize functional impairment.

\section{Acknowledgments}

This research was supported by the Basic Science Research Program through the National Research Foundation of Korea funded by Ministry of Science and ICT (NRF-2019M3C7A1032262) and by Healthcare AI Convergence Research \& Development Program through the National IT Industry Promotion Agency of Korea (NIPA) funded by the Ministry of Science and ICT (No. S1601-20-1034) to S.H.Lee.

\section{Conflicts of Interest}

The authors have no potential conflicts of interest to disclose.

\section{Author Contributions}

All co-authors have made significant contributions. Furthermore, all authors have participated in this work to responsibility for the contents and approved the final version of the paper and its submission for publication.

Conceptualization: all authors. Data curation: all authors. Formal analysis: all authors. Funding acquisition: Sang-Hyuk Lee. Investigation: all authors. Methodology: all authors. Project administration: all authors. Resources: all authors. Software: Ji Eun Kim, Sang-Hyuk Lee. Supervision: Sang-Hyuk Lee. Validation: all authors. Visualization: Hyun-Ju Kim, SangHyuk Lee. Writing_original draft: all authors. Writing_review \& editing: all authors.

\section{ORCID iDs}

Hyun-Ju Kim

Ji Eun Kim

Sang-Hyuk Lee https://orcid.org/0000-0002-8093-3366

https://orcid.org/0000-0003-0143-2633

https://orcid.org/0000-0001-7939-3000

\section{REFERENCES}

1. Bystritsky A, Kerwin L, Niv N, Natoli JL, Abrahami N, Klap R, et al. 
Clinical and subthreshold panic disorder. Depress Anxiety 2010;27: 381-389.

2. Lochner C, Mogotsi M, du Toit PL, Kaminer D, Niehaus DJ, Stein DJ. Quality of life in anxiety disorders: a comparison of obsessive-compulsive disorder, social anxiety disorder, and panic disorder. Psychopathology 2003;36:255-262.

3. Marcus SC, Olfson M, Pincus HA, Shear MK, Zarin DA. Self-reported anxiety, general medical conditions, and disability bed days. Am J Psychiatry 1997;154:1766-1768.

4. Klerman GL, Weissman MM, Ouellette R, Johnson J, Greenwald S. Panic attacks in the community: social morbidity and health care utilization. JAMA 1991;265:742-746.

5. Markowitz JS, Weissman MM, Ouellette R, Lish JD, Klerman GL. Quality of life in panic disorder. Arch Gen Psychiatry 1989;46:984-992.

6. Gloster AT, Klotsche J, Gerlach AL, Hamm A, Ströhle A, Gauggel S, et al. Timing matters: change depends on the stage of treatment in cognitive behavioral therapy for panic disorder with agoraphobia. J Consult Clin Psychol 2014;82:141-153.

7. Roy-Byrne PP, Cowley DS. Course and outcome in panic disorder: a review of recent follow-up studies. Anxiety 1994;1:151-160.

8. Davidoff J, Christensen S, Khalili DN, Nguyen J, IsHak WW. Quality of life in panic disorder: looking beyond symptom remission. Qual Life Res 2012;21:945-959.

9. Bruce SE, Yonkers KA, Otto MW, Eisen JL, Weisberg RB, Pagano M, et al. Influence of psychiatric comorbidity on recovery and recurrence in generalized anxiety disorder, social phobia, and panic disorder: a 12year prospective study. Am J Psychiatry 2005;162:1179-1187.

10. WHO. World Health Organization International Classification of Functioning, Disability and Health. Geneva: World Health Organization; 2001.

11. Ware Jr JE, Sherbourne CD. The MOS 36-item short-form health survey (SF-36): I. Conceptual framework and item selection. Med Care 1992;30:473-483.

12. Nam B. Testing the validity of the Korean SF-36 health survey. J Korean Soc Health Stat 2003;28:3-24.

13. WHO. The World Health Organization Quality of Life-100. Field Trial WHOQOL-100. Geneva: WHO; 1995.

14. The World Health Organization quality of life assessment (WHOQOL): position paper from the World Health Organization. Soc Sci Med 1995; 41:1403-1409.

15. Patrick DL, Erickson P. What constitutes quality of life? Concepts and dimensions. Clin Nutr 1988;7:53-63.

16. Uestuen B, Kennedy C. What is "functional impairment"? Disentangling disability from clinical significance. World Psychiatry 2009;8:8285.

17. World Health Organization. World Health Organization Disability Assessment Schedule (WHODASII). Training Manual: a guide to administration. Geneva: WHO (2000). Available at: http://www.who.int/ icidh/whodas/. Accessed April 9, 2003.

18. Sheehan KH, Sheehan DV. Assessing treatment effects in clinical trials with the discan metric of the Sheehan Disability Scale. Int Clin psychopharmacol 2008;23:70-83.

19. Leon A, Shear MK, Portera L, Klerman G. Assessing impairment in patients with panic disorder: the Sheehan Disability Scale. Soc Psychiatry Psychiatr Epidemiol 1992;27:78-82.

20. Leon AC, Olfson M, Portera L, Farber L, Sheehan DV. Assessing psychiatric impairment in primary care with the Sheehan Disability Scale. Int J Psychiatry Med 1997;27:93-105.

21. Sheehan D. Sheehan disability scale. Handbook of psychiatric measures 1983;2:100-102.

22. Storch EA, Larson MJ, Muroff J, Caporino N, Geller D, Reid JM, et al. Predictors of functional impairment in pediatric obsessive-compulsive disorder. J Anxiety Disord 2010;24:275-283.

23. Karsten J, Penninx BW, Verboom CE, Nolen WA, Hartman CA. Course and risk factors of functional impairment in subthreshold de- pression and anxiety. Depress Anxiety 2013;30:386-394.

24. Hollifield M, Katon W, Skipper B, Chapman T, Ballenger JC, Mannuzza S, et al. Panic disorder and quality of life: variables predictive of functional impairment. Am J Psychiatry 1997;154:766-772.

25. Jaffe A, Froom J, Galambos N. Minor depression and functional impairment. Arch Fam Med 1994;3:1081-1086.

26. Houck PR, Spiegel DA, Shear MK, Rucci P. Reliability of the self-report version of the panic disorder severity scale. Depress Anxiety 2002;15: 183-185.

27. Shear MK, Brown TA, Barlow DH, Money R, Sholomskas DE, Woods SW, et al. Multicenter collaborative panic disorder severity scale. Am J Psychiatry 1997;154:1571-1575.

28. Capron DW, Gonzalez A, Parent J, Zvolensky MJ, Schmidt NB. Suicidality and anxiety sensitivity in adults with HIV. AIDS Patient Care STDS 2012;26:298-303.

29. Stanley IH, Boffa JW, Rogers ML, Hom MA, Albanese BJ, Chu C, et al. Anxiety sensitivity and suicidal ideation/suicide risk: a meta-analysis. J Consult Clin Psychol 2018;86:946-960.

30. McNally RJ. Anxiety sensitivity and panic disorder. Biol Psychiatry 2002;52:938-946.

31. Schmidt NB, Woolaway-Bickel K, Bates M. Evaluating panic-specific factors in the relationship between suicide and panic disorder. Behav Rese Ther 2001;39:635-649.

32. Reiss S. Expectancy model of fear, anxiety, and panic. Clin Psychol Rev 1991;11:141-153.

33. Rufer M, Albrecht R, Schmidt O, Zaum J, Schnyder U, Hand I, et al. Changes in quality of life following cognitive-behavioral group therapy for panic disorder. Eur Psychiatry 2010;25:8-14.

34. Jeon JR, Lee EH, Lee SW, Jeong EG, Kim JH, Lee D, et al. The early trauma inventory self report-short form: psychometric properties of the Korean version. Psychiatry Investig 2012;9:229-235.

35. Beck AT, Steer RA, Brown G. Beck Depression Inventory-II. San Antonio, TX: Psychological Assessment; 1996.

36. Jo SA, Park MH, Jo I, Ryu SH, Han C. Usefulness of Beck Depression Inventory (BDI) in the Korean elderly population. Int J Geriatr Psychiatry 2007;22:218-223.

37. Lee EH, Kim JH, Yu BH. Reliability and validity of the self-report version of the Panic Disorder Severity Scale in Korea. Depress Anxiety 2009;26:E120-E123.

38. Lim YJ, Yu BH, Kim JH. Korean anxiety sensitivity index—revised: its factor structure, reliability, and validity in clinical and nonclinical samples. Depress Anxiety 2007;24:331-341.

39. Taylor S, Cox BJ. Anxiety sensitivity: multiple dimensions and hierarchic structure. Behav Res Ther 1998;36:37-51.

40. Deacon BJ, Abramowitz JS, Woods CM, Tolin DF. The Anxiety Sensitivity Index-Revised: psychometric properties and factor structure in two nonclinical samples. Behav Res Ther 2003;41:1427-1449.

41. Psychiatry \& Behavioral Health Learning Network. Sheehan Disability Scale (SDS). Available at: https://www.psychcongress.com/saundrascorner/scales-screeners/disability-scales/sheehan-disability-scale-sds. Accessed April 29, 2021.

42. Eguchi M, Noda Y, Nakano Y, Kanai T, Yamamoto I, Watanabe N, et al. Quality of life and social role functioning in Japanese patients with panic disorder. J Nerv Ment Dis 2005;193:686-689.

43. Telch MJ, Schmidt NB, Jaimez TL, Jacquin KM, Harrington PJ. Impact of cognitive-behavioral treatment on quality of life in panic disorder patients. J Consult C Psychol 1995;63:823-830.

44. Langs G, Quehenberger F, Fabisch K, Klug G, Fabisch H, Zapotoczky HG. The development of agoraphobia in panic disorder: a predictable process? J Affect Disord 2000;58:43-50.

45. Rapaport MH, Clary C, Fayyad R, Endicott J. Quality-of-life impairment in depressive and anxiety disorders. Am J Psychiatry 2005;162: 1171-1178.

46. Guico-Pabia CJ, Fayyad RS, Soares CN. Assessing the relationship between functional impairment/recovery and depression severity: a pooled 
analysis. Int Clin psychopharmacol 2012;27:1-7.

47. Coyne JC. Depression and the response of others. J Abnorm Psychol 1976;85:186-193.

48. Kang EH, Kim B, Choe AY, Lee JY, Choi TK, Lee SH. Panic disorder and health-related quality of life: the predictive roles of anxiety sensitivity and trait anxiety. Psychiatry Res 2015;225:157-163.

49. Chambless DL, Williams KE. A preliminary study of African Americans with agoraphobia: symptom severity and outcome of treatment with in vivo exposure. Behav Ther 1995;26:501-515.

50. Francis JL, Weisberg RB, Dyck IR, Culpepper L, Smith K, Edelen MO, et al. Characteristics and course of panic disorder and panic disorder with agoraphobia in primary care patients. Prim Care Companion J Clin Psychiatry 2007;9:173-179.

51. Lu W, Mueser KT, Rosenberg SD, Jankowski MK. Correlates of adverse childhood experiences among adults with severe mood disorders. Psychiatr Serv 2008;59:1018-1026.

52. Conus P, Cotton S, Schimmelmann BG, Berk M, Daglas R, McGorry $\mathrm{PD}$, et al. Pretreatment and outcome correlates of past sexual and physical trauma in 118 bipolar I disorder patients with a first episode of psychotic mania. Bipolar Disord 2010;12:244-252.

53. Carrion VG, Wong SS. Can traumatic stress alter the brain? Understanding the implications of early trauma on brain development and learning. J Adolescent Health 2012;51:S23-S28.

54. Kuo JR, Goldin PR, Werner K, Heimberg RG, Gross JJ. Childhood trauma and current psychological functioning in adults with social anxiety disorder. J Anxiety Disord 2011;25:467-473.

55. Westphal M, Olfson M, Gameroff MJ, Wickramaratne P, Pilowsky DJ, Neugebauer R, et al. Functional impairment in adults with past posttraumatic stress disorder: findings from primary care. Depress Anxiety 2011;28:686-695.

56. Marcaurelle R, Bélanger C, Marchand A, Katerelos TE, Mainguy N. Marital predictors of symptom severity in panic disorder with agoraphobia. J Anxiety Disord 2005;19:211-232.

57. Balázs J, Miklósi M, Keresztény Á, Hoven CW, Carli V, Wasserman C, et al. Adolescent subthreshold-depression and anxiety: psychopathology, functional impairment and increased suicide risk. J Child Psychol Psychiatry 2013;54:670-677.

58. Ettigi P, Meyerhoff AS, Chirban JT, Jacobs RJ, Wilson RR. The quality of life and employment in panic disorder. J Nerv Ment Dis 1997;185: 368-372.

59. Reilly MC, Zbrozek AS, Dukes EM. The validity and reproducibility of a work productivity and activity impairment instrument. Pharmacoeconomics 1993;4:353-365. 